\title{
Professor, NÃO VÊS QUE ESTOU QUeIMANDO?
}

\author{
Conceiçāo Aparecida Costa Azenha*
}

\begin{abstract}
RESUMO
O objetivo deste artigo é, a partir da ética psicanalítica, articular angústia e desejo como operadores necessários à educação. Nesta articulação, situamos a utopia como uma possibilidade de constituir barreira à alienação da criança ao desejo do Outro, na medida em que, caminhar na contramão de um discurso hegemônico, pode promover um despertar das ilusões (psico)pedagógicas.

Palavras-ChaVE: educação, angústia, desejo, alienação, utopia, processo de subjetivação.
\end{abstract}

Teachers. Don't you see that I'm burning?

Abstract

This article is based on psychoanalytic ethics, with the objective of articulating anxiety and desire as operators that are needed if education is to occur. A further objective in this articulation is to situate utopia as the possibility of setting up a barrier against the alienation of the child from the desire of the Other, since going against the hegemonic discourse can bring about the awakening of (psycho)pedagogical illusions.

KEY WORDS: education, anxiety, desire, alienation, utopia, process of subjectivation.

A experiência obtida junto a professores e alunos no cotidiano escolar de uma rede municipal de educação permitiu-me identificar que a angústia passou a ser queixa comum no que respeita à Educação: a "angústia" parece ser o "pão-nosso-de-cada-dia" de todo educador. O significante "angústia" é usado amplamente pelos educadores como sinônimo de sofrimento e pesar. Pode-se, no entanto, interrogar sobre o estatuto desse afeto e, por isso, a princípio, faço a opção do uso das aspas indicativas de uma precaução.

* Psicóloga e psicopedagoga da Coordenadoria Municipal de Educação de Nova Odessa/ SP, mestre e aluna do doutorado no IEL/Unicamp. E-mail: cissazenha@terra.com.br 
Sabe-se que, a despeito de toda dificuldade que o ofício de educar sempre colocou a seus agentes, nem sempre os professores se sentiram tão mal na própria pele como atualmente. Nesse sentido, recorrer à História social da criança e da família - um clássico de Ariès (1981) - pode ser bastante esclarecedor: com a Modernidade, a criança passou a ocupar o lugar de realização do desejo dos pais, e a infância passa a ser vislumbrada como o melhor periodo da vida, numa compensação imaginária de um presente às vezes não muito satisfatório para o adulto. Seguindo de perto o autor, pode-se notar que depois dos Tempos Modernos, houve uma produção de discursividades sobre a criança, até então inexistentes; o lugar social da criança assume, então, um papel bem distinto do que lhe era reservado na Idade Média, quando os pequenos, assim como as mulheres, eram trocados ou oferecidos como animais e mercadorias, em uma época em que o parentesco apenas definia a herança, mas não era tomado como critério de tutela e educação das crianças. A criança só passava a fazer parte da vida social depois que os embaraços de sua primitiva condição física já tivessem passado, ou seja, quando ela já pudesse "se virar" sozinha. Por volta dos sete anos, ela voltava para a família original como um mini-adulto, participando dos jogos e trabalhos do grupo. No final do século XVI, houve um movimento moralizante por parte dos católicos e protestantes que viam na infância outra possibilidade: o pequeno educar, para, quando ficar grande, do caminho não se desviar (ditado popular inspirado no Evangelho); em outras palavras, tomar a infância como uma instância privilegiada para a construção de um homem melhor. O Estado deveria se responsabilizar por isso. Os elementos mais importantes desse movimento foram a Reforma Luterana, a Contra-Reforma Católica e o Estado Moderno. Antes desse movimento, no entanto, a infância não era considerada uma etapa importante da vida, à qual fossem necessários um lugar e propósitos específicos de educação.

Pela letra de Ariès (1981), identificamos que a criança foi se tornando, pouco a pouco, a sustentação e o emblema dos ideais de seus pais, que têm na educação escolar e na medicina importantes parceiros para o alcance dessa meta. A partir do Renascimento, os textos já apontam os ideais do que seria uma boa educação: Didactica Magna, de Comenius (15921670); Ensaio sobre o Entendimento Humano, de Locke (1632-1704), e, em posição de destaque, Emilio ou da educação de Rousseau (1712-1778). Desde então, toda essa discursividade, não raro, força os adultos a satisfazerem o tempo todo os desejos da criança, com o argumento de que só 
agindo assim podem ser bons pais e professores. No entanto, o que temos visto atualmente é que o relevo dado à criança, muitas vezes submete a educação a um fato de difícil acontecimento, justamente pela anulação da diferença entre adultos e crianças.

Para que uma educação aconteça é preciso que haja uma inversão da demanda educativa, ou seja, é preciso que a criança, diante do adulto que quer ensinar, possa querer aprender. Tal inversão - de alguém que quer ensinar para alguém que quer aprender - não acontece se a criança não estiver em certa posição subjetiva, qual seja, a de sujeito desejante e não em uma posição objetal de uma empreitada do Outro. Tampouco acontece se o educador não puder reconhecer a dívida simbólica que contraiu ao ser, ele mesmo, educado por um Outro. Reconhecer tal dívida implica em um duplo sentido: por um lado, implica o reconhecimento de sua "heteronomia radical" (Lacan, 1998, p. 528) ao Outro - castração - e, por outro, a impossibilidade de vir a encarnar o falo, ou seja, encarnar tudo aquilo que faz falta ao sujeito, devolvendo-lhe uma suposta completude.

Importa ressaltar que, pela abordagem psicanalítica aqui privilegiada, desejo não coincide com vontade. Nesse sentido, a psicanálise esclarece que se há caminhos para o desejo, não são sem passar pela angústia. É nesse ponto que procuro articular a noção de angústia, desejo e discurso pedagógico, para retomar a falta e as produçōes possíveis entre professor e aluno.

Em reuniōes com professores, cujo propósito da solicitação de minha presença era o de discutir as dificuldades de aprender centradas nas "crianças-problema", escuto as queixas que vão sendo enunciadas e as justificativas em contraponto: "a causa dessa calamidade está na família e nas condiçôes sociais do país"; "se o professor faz a sua parte e o aluno não aprende, é por falta de interesse ou problemas psicológicos do aluno"; "quando tento e não consigo nada, fico deprimido, já pedi até afastamento" (Azenha, 2006b).

O que depreendo dessas justificativas é que falta algo na relação do educador com a criança; falta saber o que a criança quer; falta alguma coisa à criança; faltam condiçôes, faltam melhores cursos de capacitação aos professores; falta principalmente um saber aos professores, falta... Todos localizam essa "angústia" naquilo que falta e, quase em coro, pedem à psicanálise algo como uma solução, justamente em um tempo em que as notícias sobre o ensino no país são sempre lidas como um sinal de perigo, como os resultados oficiais sobre os índices da Educação em nosso país, realizados pelo Instituto Nacional de Pesquisas Educacionais Anísio Texeira (INEP) - por exemplo. 
32 Revista Solta a Voz, v. 18, n. 1

Fico pensando se toda essa conjunção não põe em risco o papel do professor que, colocado sob suspeita, perde seu revestimento simbólico, suporte necessário para um endereçamento da criança ao adulto em seu desejo de saber. A criança precisa poder supor um saber a seu professor, saber esse que, embora não existia, a partir da oferta do professor, passa a fazer falta ao aluno que, então, passa a desejá-lo. No entanto, se o professor está sob suspeita, algo de uma indistinção entre adultos e crianças comparece, igualando-os e, dessa forma, professor e aluno alternam-se nas posições de depositários da esperança de um futuro melhor e de bode expiatório do fracasso escolar.

Se não cabe à ética psicanalítica recomendar ou prescrever algo à educação - porque, de fato, não é disso que se trata - a psicanálise pode iluminar o que está em jogo na cena educativa: a certeza da falta (nomeada em cada objeto que poderia supostamente complementá-la) ligada à falta de certeza quanto ao que fazer com esse mal-estar. Nesse sentido, é na relação com a falta que a angústia (aqui escrita sem as aspas) é tratada por Lacan em seu décimo seminário, em 1962; elaboração preciosa justamente porque permite desfazer um mal-entendido alimentado pelo capitalismo de nossos dias: angústia não equivale a um sofrimento ligado à certeza de que algo falta; pelo contrário, durante todo seu seminário, Lacan (2005) nos ensina que a angústia justamente aparece quando a falta está obliterada, ou seja, quando falta a falta. Desde Freud sabemos que o sofrimento pode ser curado, mas não o mal-estar, como aquele da angústia constituinte de todas as inter-relações humanas, como já apontado, condição necessária para a produção de desejo.

Acredito que tal sofrimento dos professores pode ser colocado em contínuo à sua adesão apressada à demanda da empresa pedagógica moderna, ou seja, a de formar indivíduos autônomos e competentes, por meio de um método científico aplicado à educação.

Se no passado a educação se pautava pela Filosofia, hoje quem dá as cartas é a ciência, e a visibilidade do modelo científico transforma-se em um ideal para o campo da educação. Visando produzir um adulto a quem nada falte, a pedagogia faz apelo ao conhecimento científico acerca do comportamento infantil. O discurso (psico)pedagógico hegemônico, conforme elaborou Lajonquière funda-se na ilusão de o adulto poder calibrar suas intervençôes pedagógicas, seguindo a tese de adequação natural, de modo a poder oferecer à criança, no devido tempo, a satisfação de suas necessi- 
dades. Explicando melhor, segundo o autor, o discurso (psico)pedagógico hegemônico constitui-se com o seguinte princípio: a partir do conhecimento científico da criança, por meio da psicologia do desenvolvimento, pode-se estabelecer um programa de ensino que seria realmente eficaz. Tal programa, baseado nos estágios de desenvolvimento, poderia, segundo esse discurso, oferecer exatamente aquilo de que a criança precisa, nem mais nem menos, nem cedo, nem tarde, para que no futuro ela venha a ser um adulto a quem nada falte. Esse discurso circula em diversos cursos de formação continuada e nos cursos de graduação ou pós-graduação da área da Educação. Entretanto, como o autor, pode-se constatar no cotidiano escolar que, quanto mais inflacionada está a dimensão psicopedagógica, mais fica comprometida a educativa. Vale a pena citá-lo:

Renunciar à educação não é um ato volitivo. Aquilo que chamamos de discurso (psico)pedagógico hegemônico é uma forma de se pensar a problemática educativa que leva embutido esse gesto de renúncia.

Por que (psico) entre parênteses?

Aquilo que hoje diz-se, sustenta-se, imagina-se como dever a ser cumprido ou possibilidade a ser gestada no interior do campo educativo - ou seja, a mesmíssima pedagogia, pois ela sempre foi uma reflexão mais ou menos sistemática sobre os fins e os meios da educação - está atravessado pelas ilusōes próprias dos saberes psicológicos modernos. [...] Dessa forma, quem sabe sobre a educação e portanto fala como especialista na matéria é o (psico)pedagogo - suposto detentor de uma série de saberes "psi" aplicados que possibilitariam calcular os efeitos psicodesenvolvimentistas das metódicas intervençôes "educativas" colocadas em ação (Lajonquière, 1999, p. 29).

A autonomia dos sujeitos é a bandeira de toda escola moderna. No entanto, a psicanálise, por operar justamente naquilo que, por estrutura, fica de fora das teorias psicológicas e pedagógicas e que a clínica nos dá a ver - a singularidade dos sujeitos - revela que a criança resiste a toda simbolização, pois como observa Leite,

O funcionamento do aparelho psíquico da criança não obedece à lógica presente na noção de desenvolvimento ou à lógica de um movimento que partindo de um estado de imaturidade ou imperfeição conduziria a um funcionamento complexo superior [...] a criança, longe de constituir um estado incompleto da estrutura psíquica, é um sujeito produzido pelo desejo inconsciente (Leite, 2005, p.7-8). 
Entendo que o que fica elidido do discurso pedagógico é, em sentido amplo, o fato de que em toda educação há a produção de um resto; de algo que escapa a qualquer tentativa de formalização. E esse é um efeito da própria linguagem; não é opção do sujeito: é a sua condição.

$\mathrm{Na}$ tentativa vã de obter uma resposta sobre o enigma da origem do humano, de voltar ao estado natural das coisas, de ver o real da criança, o adulto olha nos olhos dela esperando ver neles refletido o que deve oferecer para que nada falte a ela; nessa espera, como gosta de dizer Lajonquière, $\mathrm{o}$ adulto se demite do ato de educar. Na vigência de tal discurso, o educador recusa o desejo da criança, oferecendo-lhe, de maneira narcísica, o que entende ser a sua real necessidade e, dessa forma, coloca-a na posição de objeto, dificultando-lhe sobremaneira o tornar-se sujeito do seu próprio desejo.

As culpas e dívidas sentidas pelos professores se multiplicam por não conseguirem corresponderem ao ideal proposto pelas teorias psicopedagógicas uma vez que se é de fato impossível vir a usufruir a certeza a priori quanto a uma educação bem-sucedida também é "impossível renunciar, em última instância, ao desejo que assim não seja" (Lajonquière, 2000, p.106). O infortúnio dos educadores parece ser, hodiernamente, o de viver como uma impotência imaginária, o que é da ordem de uma impossibilidade estrutural.

A certeza advinda dos manuais técnicos sobre a psicologia da criança impede a fecunda dúvida que acompanha a angústia produtora de novos conceitos, tornando a educação um fato de difícil acontecimento. No lugar da falta de saber sobre a criança, a educação moderna coloca as teorizaçōes psicodidáticas, tamponando-a, uma vez que as mesmas "pretendem funcionar como anteparo perante a angústia que a educação de uma criança acessa em nós" (Lajonquière, 2002, p.11). Uma vez tamponada a falta, a angústia - que pode portar um sofrimento por vezes insuportável - torna-se inarredável para o professor, e, muitas vezes, talvez não reste ao aluno outra posição a não ser aquela de pagar com sua própria existência a dívida simbólica ao Outro.

Em seu artigo "O homem sem qualidades", Edson Sousa (2005) lembra que certos movimentos tendem a se anular mutuamente. Tais movimentos podem ser ilustrados, segundo o autor, pelas palavras de Musil:

A humanidade produz bíblias e armas, tuberculose e tuberculina. É uma democracia com reis e aristocratas; constrói igrejas, mas constrói universidades que as combatem; transforma mosteiros em casernas, mas nas ca- 
sernas coloca capelães militares; naturalmente também coloca nas mãos de bandidos mangueiras de borracha recheadas de chumbo, para atormentarem outras pessoas, e depois prepara cobertores macios para as vítimas de "maus-tratos" (Musil, 1989 apud Sousa, 2005).

Depurados em uma fórmula matemática, situações como as de produção de bíblias e de armas equivaleriam a 1-1, cujo resultado, naturalmente, seria zero: ou seja, tudo ficaria idealmente equacionado, sem nenhuma questão a resolver, a qual poderia convocar os sujeitos a um lugar, uma implicação, uma responsabilidade por uma escolha. Talvez seja um exagero aumentar essa série de Musil, relacionando ainda: produz infância para permitir o erro, mas constrói escolas para dar notas às crianças; produz uma ampla diversidade para as atividades infantis, mas também produz ritalina; defendo o direito da criança brincar, mas indica brinquedos pedagógicos porque é capital que ela não perca tempo para aprender; coloca criança como centro da esperança de um futuro melhor, roubandolhe o presente que naturalmente é o ideal dos adultos.

Seria mesmo um exagero?

Vale lembrar que essa tendência de anulação também fracassa, felizmente. Há resto. É justamente o resto dessa operação - que a vida coloca aos nossos olhos de forma não zerada - que sempre pulsiona a vida a seguir em frente, por sua contingência impossível de simbolização a qual, justamente, força a produção de cultura.

Sousa nos alerta ainda que a função da utopia é justamente a de esperançar, ao produzir furos nos conceitos estabelecidos, abrindo possibilidades para o surgimento de outros conceitos. Vale a pena citá-lo: "A utopia é aqui pensada como marca maior da função da cultura, ou seja, aquela que ainda sabe cultivar o solo e que, mesmo que possa planejar o plantio, não sabe exatamente qual será o contorno e a dimensão da colheita” (Sousa, 2006, p.170).

Pode-se reencontrar nas belas palavras do autor o caráter de impossibilidade a priori de um empreendimento, seja ele qual for e, neste ponto, é impossível não lembrar do aceite de Freud ao clássico mote das três profissões impossíveis - educar, curar e governar. Lembrança preciosa ao que aqui apresento, pois justamente concerne àquilo que não se dobra a qualquer planejamento, ainda que cientificamente estabelecido. Nesse ponto, não é demais lembrar que toda hegemonia como discurso do instituído é 
contraproducente pelo seu caráter de saber morto e quanto "o ir pela contramão" - característico de um agir pela ética da utopia - pode favorecer o processo criativo, vívido: dessa forma, inventar sempre é a nossa condição ou condenação! Não fosse assim, o caráter inovador de cada invenção cultural rapidamente se transformaria (e se transforma mesmo, pela busca do poder) na mesmice de sempre, produzindo catástrofes, como menciona Sousa (2006), citando Walter Benjamin.

Nesse sentido, a utopia pode constituir uma barreira à alienação da criança ao adulto; alienada, em posição de objeto do desejo do Outro, uma produção como sujeito desejante fica vedada à criança. Assim, a ética psicanalítica e o fazer utópico podem coincidir na medida em que andar na contramão do discurso (psico)pedagógico hegemônico diz respeito a refutar a aplicação de um modelo científico ao fazer do educador, haja vista que, ao escutar o sujeito, o que a psicanálise visa é justamente resguardar o seu lugar, dando-lhe vez e voz. Mas, talvez seja também, apelar ao que da Arte possa se relacionar com o ofício do educador: um estilo. Vale lembrar que, para Lacan, o estilo é o próprio "homem", cuja mensagem vem do Outro e cujo lugar comporta sua divisão. Com Lacan, pode-se pensar que a arte-ofício do educador - com o estilo que seu endereçamento impóe - leva-o a uma conseqüência em que ele precise colocar algo de si na leitura que faz da educação.

A barreira à alienação pode acontecer justamente pela manutenção da aposta no sujeito e não no discurso (psico)pedagógico. As narrativas infantis, a produção aparentemente desarmônica da criança e o rébus que ela produz com seus gestos, falas e desenhos são momentos privilegiados do que excede a qualquer teoria e planejamento, funcionando como uma resistência ativa da criança que, alternando posiçóes, presenças e ausências, pode criar sua via de separação do desejo do Outro, estruturando sua subjetividade.

Nesse ponto, cabe dar voz a um aluno que pude acompanhar (Azenha, 2006a) e que fazia parte da Recuperação de Ciclo - nome adotado pela Secretaria Estadual de Educação para designar a classe de alunos repetentes pela segunda vez na $4^{a}$ série. Muitos dos alunos dessas salas não sabiam ler mas nem por isso, não tinham algo a dizer ou fazer. Reproduzo aqui um desses dizeres, produzido em texto por um aluno:

O professor

O professor está contando uma história

E um aluno começa a dormir

O professor irá sacudi-lo 
Irá repreendê-lo?

Não

O professor abaixa a voz

Para não acordá-lo. (Azenha, 2006a, p.59)

O professor abaixa a voz, diz o aluno. Interessante apontar que, como lembra Lacan, a voz é justamente a borda entre a angústia e o desejo! Talvez seja lícito pensar que o poema revela que os alunos ficam entre o "duro desejo de durar" (Lacan, 1992, p. 54) desse sono, e o desejo de despertar. A voz que pode estabelecer laços e causar o desejo - revela o poema - é abaixada. Pode-se pensar ainda qual seria a função desse despertar. Lacan enfatiza que o sonho descrito por Freud para defender sua tese de realização de desejos é justamente um sonho que faz despertar. Cito-o:

um pai estivera de vigília à cabeceira do leito de seu filho enfermo por dias e noites a fio. Após a morte do menino, ele foi para o quarto contíguo para descansar, mas deixou a porta aberta, de maneira a poder enxergar de seu quarto o aposento em que jazia o corpo do filho, com velas altas a seu redor. Um velho fora encarregado de velá-lo e se sentou ao lado do corpo, murmurando preces. Após algumas horas de sono, o pai sonhou que seu filho estava de pé junto a sua cama, que o tomou pelo braço e lhe sussurrou em tom de censura: "Pai, não vês que estou queimando?" Ele acordou, notou um clarão intenso no quarto contíguo, correu até lá e constatou que o velho vigia caíra no sono e que a mortalha e um dos braços do cadáver de seu amado filho tinham sido queimados por uma vela acesa que tombara sobre eles (Freud, [s.d., s.p.]).

Como alerta Lacan, o sonho - ao cumprir a função de guardião do sono - impede o sujeito de despertar: "o despertar nos mostra o despontar da consciência do sujeito na representação do que se passou - o deplorável acidente da realidade, ao qual não se pode fazer mais do que acorrer!" (Lacan, 1985, p. 60). Ainda segundo Lacan (1992, p. 54), o inconsciente é muito exatamente a hipótese de que a gente não sonha somente quando dorme, pois "só acordamos para continuar sonhando no real, ou para ser mais exato, na realidade". Assim, podemos pensar que nesse sonho, tela da cena educativa, o professor parece recobrir a angústia que a criança atualiza, servindo-se dos manuais psicopedagógicos e, desta forma, parece não escutar que os alunos dizem: "professor, não vês que estou queimando?”. 
38 Revista Solta a Voz, v. 18, n. 1

Diante do apelo das crianças, expresso pelas mais diversas formas, mídias, relatórios e relatos pessoais, podemos continuar sonhando com um futuro melhor que as crianças de hoje irão construir um dia ou despertar para a realidade de que o mundo é construído pelos adultos às crianças. Despertos, paradoxalmente, poderemos sonhar, realizando desejos de (re)inventar já as formas de transmitir cultura, marcas simbólicas aos alunos. Quem sabe o desejo de despertar não possa, enfim, despertar o desejo das crianças e a educação possa acontecer não apenas como exceção, de maneira pontual. Como se vê, não são apenas os alunos que estão queimando.

\section{REFERÊNCIAS}

ARIÈS, P. História social da criança e da família. 2. ed. Rio de Janeiro: Guanabara, 1981.

AZENHA, C. A. C. Lia: do nome ao verbo. Ou: desejo e leitura. 2006. 178 f. Dissertação (Mestrado em Lingüística) - Instituto deEstudos da Linguagem, Universidade Estadual de Campinas, Campinas, 2006a. Disponível em: $<$ http://libdigi.unicamp.br/document/?code=vtls000397289>. Acesso em: 29 jun. 2007.

(La)Langústia do discurso pedagógico. In: LEITE, N. V. A. (Org.). Corpolinguagem: angústia: o afeto que não engana. Campinas-SP: Mercado de Letras, 2006b. p. 241-252.

FREUD, S. A interpretação dos sonhos. In: Obras completas. São Paulo: Imago, [s.d.]. Edição Eletrônica Brasileira. CD-ROM. Edição Eletrônica das obras psicológicas completas de Sigmund Freud. Com comentários e notas de James Strachey, Direção da edição brasileira de Jayme Salomão e coordenação da Edição Eletrônica Brasileira de Eduardo Salomão.

LACAN, J. O seminário, livro 11: os quatro conceitos fundamentais da psicanálise. Trad. M.D. Magno. Rio de Janeiro: Jorge Zahar, 1985.

O seminário, livro 17: o avesso da psicanálise. Trad. Vera Ribeiro.

Rio de Janeiro: Jorge Zahar, 1992.

Escritos. Trad. Vera Ribeiro. Rio de Janeiro: Jorge Zahar, 1998.

O seminário, livro 10: a angústia. Trad. Vera Ribeiro. Rio de Janeiro:

Jorge Zahar, 2005. 
LAJONQUIÈRE, L. Infância e ilusão (psico)pedagógica: escritos de psicanálise e educação. 2. ed. Petrópolis: Vozes, 1999.

. Itard Victor!!! Ou do que não deve ser feito na educação. In: BANKSLEITE, L.; GALVÃO, I. A educação de um selvagem. As experiências pedagógicas de Jean Itard. São Paulo: Cortez, 2000. p.105-116.

Apresentação. In: BACHA, M. N. A arte de formar: o feminino, o infantil e o epistemológico. Petrópolis, RJ: Vozes, 2002. p. 9-12.

LEITE, N. V. A. A clínica psicanalítica com crianças. 2005. Inédito. Trabalho apresentado durante o I Encontro do Núcleo de Formação da Clínica de Linguagem: A fala da criança - o Sujeito - a Língua, realizado pelo Núcleo de Formação da Clínica de Linguagem, São Paulo, em 05/08/2005.

SOUSA, E.L.A. O homem sem qualidades. Freud-lacan.com. Association Lacanienne Internationale, Paris, 31 out. 2005. Disponível em: <http:// www.freudlacan.com/articles/article.php?url_article=edesousa311005>. Acesso em: 24 jul. 2007.

. Furos no futuro: utopia e cultura. In: SCHÜLER, F.; BARCELLOS, M. (Orgs.). Fronteiras: arte e pensamento na época do multiculturalismo. Porto Alegre: Sulina, 2006. p. 167-180.

Recebido em: 2 abr. 2007

Aceito em: 17 mai. 2007 